\title{
Mental health in Canada: out of the shadows forever
}

\section{Michael Kirby PhD}

1 anada is the only G8 country that does not have a national mental health strategy. This startling fact was one of the findings of the investigation of mental health in Canada by the Standing Senate Committee on Social Affairs, Science and Technology. Equally shocking is the fact that the Senate committee's report Out of the Shadows at Last is the first national report on mental health, compared with more than 300 reports on the physical health system.

Among the report's many recommendations is the creation of a mental health commission to act as a catalyst for change. Mental health has been neglected for far too long in Canada, and the need for immediate action is broadly recognized across the mental health sector - by people living with mental health problems, their family members and caregivers, professionals, researchers and governments.

In August 2007, the prime minister announced the creation of the Mental Health Commission of Canada ${ }^{2}$ to a standing ovation during a plenary session of the International Initiative for Mental Health Leadership conference. This commission will be a very important for focusing attention, dialogue and action over the next decade to ensure that mental health stays out of the shadows forever.

The federal government has agreed to fund the commission's work (committing \$15 million a year once the commission is fully operational), and the commission has been endorsed by all of the provincial and territorial governments (with the exception of Quebec). However, the commission will operate at arm's-length from all levels of government.

\section{Strategic initiatives}

The commission has 3 strategic initiatives that flow from the Senate committee's recommendations: develop a national mental health strategy, conduct a Io-year anti-stigma campaign, and build a national knowledge-exchange centre.

In developing a national strategy for Canada, the commission will be able to learn from the experience of other countries, such as Australia, New Zealand and the United Kingdom. Moreover, Out of the Shadows at Last provides an invaluable reference point for the commission as it examines the mental health services available in Canada and identifies what is needed to fill the gaps in care.

The process of developing a national strategy will take about 3 years, and the commission will consult extensively with all stakeholder groups. The overall goal of the strategy is to show how to better coordinate and integrate efforts to improve the lives of people living with a mental illness and their families.

The national strategy will reflect the fact that each province and territory is responsible for most health care delivery. The

\section{Key points}

- In 2007, the Mental Health Commission of Canada was created as a catalyst for a national discussion about mental health in Canada.

- The commission has 3 strategic initiatives: develop a national mental health strategy, combat stigma and discrimination and promote knowledge exchange.

- Stigma is a widespread problem in Canada, including among health care workers and mental health care workers.

- People with direct experience with mental health problems are integral to all activities of the commission.

strategy will provide a common set of principles, as well as effective, practical strategies that can be implemented by each jurisdiction in keeping with its own circumstances. The commission will devise a plan for change, but it will be up to others - including health care providers - to implement it. However, the wide consultation process during development should provide broad support for its implementation.

The second strategic initiative is a campaign against the stigma of mental health and the discrimination experienced by people with mental health issues. This will be an ongoing activity throughout the life of the commission. People with mental health issues can experience serious, debilitating and persistent stigma and discrimination from all parts of society, including family members, coworkers, neighbours, friends and health care providers.

International data confirm that stigma and discrimination have devastating effects and must be addressed at many levels. Stigma is found across society: in schools, health care centres, criminal justice facilities and workplaces as well as in obtaining health care services. It will be essential for health care professionals to work with the commission to understand and combat stigma everywhere, including among their own colleagues.

The commission has begun to examine the various dimensions of mental health stigma. Discussions have been held with people from other countries with experience in campaigns against mental health stigma, and existing programs and initiatives from across Canada have been identified. The commission has built the foundation for developing a

Dr. Kirby is Chair of the Mental Health Commission of Canada, Ottawa, Ont.

Une version française de cet article est disponible à l'adresse www.cmaj.ca/cgi/content/full/I78/10/I320/DCI 
uniquely Canadian effort to reduce stigma and eliminate discrimination through this process.

The third strategic initiative is knowledge exchange, which will be an important aspect of all the commission's activities. A knowledge-exchange centre will act as a communications hub to give Canadians of all backgrounds and interests the means to communicate effectively with the commission and to build communities of mutual interest. Information on a wide range of topics will be available, with links to other websites and information centres. Important documents, such as briefs, policy documents, position papers and evidence-based best practices, will be available. People will also be able to provide input about commission initiatives, such as the national strategy. An important focus will be the dissemination of best and promising practices that draw on the best science available.

\section{Supply and demand for mental health services}

It is obvious that all health care professionals play a pivotal role in promoting wellness - mental as well as physical and assisting people live their lives to the fullest potential. Health care professionals want what is best for their clients and patients, yet often the systems in place do not allow this to happen. The commission needs health care professionals and their associations to work closely with us to solve these problems of barriers to access to services.

Supply and demand is a serious challenge. As mental health becomes increasingly out of the shadows, the demand for wellness and prevention programs as well as treatment and disability management will increase substantially. Canada does not have enough mental health service providers.

Service providers will need to work closely with the commission to find new ways to address the increased demand while providing high-quality services based on the best available evidence. Although we will never be able to give everyone everything they would like, Canada must provide more for so many who are currently without.

There is a desperate need for providers to work closely together as teams and to support family caregivers and peer helpers. Domestic and international models of collaboration go well beyond the traditional biomedical model. It will be imperative for physicians to change practice patterns to embrace these new realities. For example, family physicians are the initial point of contact for about $85 \%$ of people with mental health problems. This heavy reliance on family physicians stems from the way we organize the public funding of services in Canada and puts a great burden on these family physicians. We need to change how people access services, and we need to help family physicians, in collaboration with other providers and mental health specialists, become better able to address the wide range of mental health issues.

\section{Mental health among health care providers}

It is clear that many providers of mental health services are themselves experiencing high levels of stress and other mental health problems. Studies undertaken by independent sci- entists and national organizations such as the Canadian Medical Association attest to this fact. This is a real concern. The mental well-being of mental health care providers will be an important issue for the commission to address.

It is well known that mental heath issues directly affect one's physical health and vice versa. For far too long in Canada, we have partitioned physical and psychological health; we have severed the head from the body. This is both counterproductive and harmful. The commission will be looking for ways to bring the physical and psychological domains more closely together in a more integrated approach. It is time we put the head back on the body.

Stigma is a serious issue. Tragically, testimony to the Standing Senate Committee and from other countries underscores the unsettling fact that stigma exists among all health professionals including mental health professionals. Some of the people most able to help those with mental health problems appear to hold negative attitudes toward them. The reasons for this stigma are likely varied and may include a lack of knowledge, past negative experiences, overwork, poor working condition. The commission takes this issue extremely seriously and will need the help of patients and health care providers to address it effectively.

\section{Recovery}

There is a strong international consensus that recovery is an important concept for people with mental health problems. It implies a commitment to the principle that people should be helped to live their lives to the fullest extent possible within the limitations of their illness.

Recovery requires appropriate patient support, including peer-to-peer support, family or caregiver support, community interventions and supportive housing programs. Recovery requires a departure from traditional service delivery models and it requires working "with" patients, not seeking to solve their problems for them or to simply reduce their symptoms.

The commission will need the help of physicians and their organizations to solve these important problems facing Canadian society. The demand is great. The neglect is horrific.

\section{The commission}

The commission is governed by a board of directors. The board includes II nongovernmental directors selected from a pool of over 500 applicants. In addition, there are 6 board members appointed by the provincial and territorial governments to ensure a strong link with these jurisdictions. The board is widely representative of the mental health community and includes people living with mental health problems, family caregivers, peer-support workers and service providers. There is substantial representation of Canada's Aboriginal population.

The commission has 8 advisory committees on science, children and youth, seniors, family issues, the workplace, the law, service-delivery systems, and First Nations, Inuit and Metis people. The commission intends to develop models of collaboration between health, education, the workplace, the 
private sector, the not-for-profit sector, social services and criminal justice services.

An important question is "Why do we not have an advisory committee for people who have mental health problems?" The commission stresses that people with mental health issues are at the very centre of the commission and all of its activities. These people are well represented on the board and they sit on each of the advisory committees. This structure ensures that their voice is heard throughout the commission, not just in a single advisory committee.

The commission will be a catalyst for change; potentially the most potent catalyst for mental health change in Canadian history. However, the commission is neither a service-delivery organization nor an advocacy group. It provides jurisdictions and stakeholders with the necessary tools and information needed to improve the quality of and access to mental health services and support. It will facilitate a Io-year national dialogue on mental health and mental illness in Canada. Through its efforts, the commission intends to foster and support real change across Canada. However, the actual implementation of programs and services is the responsibility of others.

\section{Conclusion}

There will be major challenges facing the commission. The commission has no power to impose its vision or strategy.
Stigma, misunderstanding and discrimination are widespread and hard to change. Resources are finite and the window of opportunity for change will not be open indefinitely. There are many jurisdictions and stakeholders whose support is crucial.

Despite with these challenges, I am confident that the job will get done. Directly or indirectly, every Canadian has been touched by mental health problems or illness. Far too many people have been unable to get the help they need. The country is ready for change: The time has come.

This article has been peer reviewed.

Competing interests: None declared.

\section{REFERENCES}

I. The Standing Senate Committee on Social Affairs, Science and Technology. Out of the shadows at last: transforming mental health, mental illness and addiction services in Canada. The Committee: 2006. Available: www.parl.gc.ca/39/r/parlbus /commbus/senate/com-e/soci-e/rep-e/repormayo6-e.htm (accessed 2008 Apr I).

2. The Mental Health Commission of Canada. Ottawa (ON): The Commission. Available: www.mentalhealthcommission.ca/mhcc.html (accessed 2008 Apr I).

Correspondence to: Dr. Michael Kirby, Mental Health Commission of Canada, Suite I80o, I030I Southport Lane SW, Calgary AB T2W IS7; fax 6I3-798-2989; mkirby@mentalhealthcommission.ca 